\title{
RECENT DECLINES IN INFANT AND NEONATAL MORTALITY IN TURKEY FROM 2007 TO 2012: IMPACT OF IMPROVEMENTS IN HEALTH POLICIES
}

\author{
Dilek Dillii ${ }^{1}$, M. Rıfat Köse ${ }^{2}$, R. Coşkun Gündüz ${ }^{3}$, Sema Özbaş ${ }^{4}$, Başak Tezel ${ }^{4}$, Nurullah Okumuş ${ }^{1}$ \\ ${ }^{1}$ Department of Neonatology, Dr. Sami Ulus Maternity and Children Research and Training Hospital, Ankara, Turkey \\ ${ }^{2}$ Board of Health Policies, Ministry of Health, Ankara, Turkey \\ ${ }^{3}$ Department of Paediatric Emergency, Ankara Children's Hematology Oncology Training and Research Hospital, Ankara, Turkey \\ ${ }^{4}$ Department of Child and Adolescent Health, Public Health Agency, Ministry of Health, Ankara, Turkey
}

\begin{abstract}
SUMMARY
Background: Infant mortality rate (IMR) and neonatal mortality rate (NMR) are accepted as good indicators to measure the health status of a nation. This report describes recent declines in IMR and NMR in Turkey.

Methods: Data on infants who died before 12 months of life were obtained from the Infant Mortality Monitoring System of Ministry of Health of Turkey between 2007 and 2012. A total of 94,038 infant deaths were evaluated.

Results: Turkey IMR and NMR exhibited a marked decline from 2007 (16.4 and 12.2) to 2010 (10.1 and 6.6) and then plateaued in 2012 (9.7 and 6.3), despite regional differences. Prematurity, congenital anomalies and congenital heart diseases (CHD) were the three most common causes of infant deaths between 2007 and 2012. While the rates of respiratory distress syndrome (RDS), sudden infant death syndrome (SIDS), and metabolic diseases increased, the rates of congenital anomalies and birth injuries decreased. IMR and NMR significantly increased with the number of infants per paediatrician, per doctor, and per midwife, while was decreasing with the increased rate of hospital birth, caesarean delivery, antenatal care, infant follow-up, and staff trained within the Neonatal Resuscitation Programme (NRP).

Conclusion: From 2007-2012, Turkey showed remarkable encouraging advances in reducing IMR and NMR. Any interventions aimed at further reductions in IMR and NMR should target the common causes of death and defined risk factors especially in socioeconomically disadvantaged regions.
\end{abstract}

Key words: infant, neonatal, mortality, health policies

Address for correspondence: D. Dilli, Department of Neonatology, Dr. Sami Ulus Hastanesi Babür Caddesi Altındağ, Ankara, Turkey. E-mail: dilekdilli2@yahoo.com

http://dx.doi.org/10.21101/cejph.a4097

\section{INTRODUCTION}

Infant mortality rate (IMR) and neonatal mortality rate (NMR) are accepted as good indicators to measure the health status of a nation (1). In Turkey, during the past 20 years there has been marked improvement in the management of maternity, pregnancy, delivery, birth, and neonatal and infantile health care by a qualitative improvement in obstetric, perinatal, neonatal, and paediatric medical conditions. Under-5 mortality (U5MR) in Turkey fell sharply from 72.0 per 1,000 live births in 1990 to 15.0 in 2011, and IMR fell from 60.0 in 1990 to 12.0 in 2011 (1). Despite small differences, these values were similar to those from the Ministry of Health of Turkey, which were 77.2 per 1,000 live births in 1988, 26.0 in 1998, and 10.1 in 2010 (2). The reductions in IMR and NMR achieved by Turkey from 1990-2010 were greater than those achieved by other E7 countries (China, India, Brazil, Mexico, Russia, Indonesia, Turkey) (3). Improved health policies on preventable issues have played a major role in this decline.

In 2003, the Ministry of Health designed and introduced the Health Transformation Programme (HTP) that sought to establish the right to good health and universal health coverage as an integral part of citizenship $(4,5)$.
There is a need for systematic analysis on the recent changes in IMR and NMR over the past six years in Turkey, which makes it important to review the differences in the causes of infant mortality (IM) and neonatal mortality (NM) and understand the current state. Therefore, we attempted to analyze the changes in IMR and NMR in Turkey from 2007-2012 with evaluating the impact of improvement in health policies.

\section{MATERIALS AND METHODS}

The numbers of live births, stillbirths, premature births, and neonatal and infant deaths in Turkey were extracted from databases of the Turkish Statistical Institute and Ministry of Health of Turkey $(2,6)$. Since there were no absolute data on the number of premature birth in Turkey, it was calculated from the previously reported premature birth rates (7).

The descriptions of mortality rates were based on the International Statistical Classification of Diseases (ICD-10) and Related Health Problems of the World Health Organization (WHO) (8).

To analyze IMR and NMR we used the national database of the Ministry of Health, Public Health Agency, Department of Child 
and Adolescent Health (DCAH) (formerly known as Maternal and Child Health and Family Planning General Directorate, MCHFP) from 2007 to 2012. In 2005, DCAH prepared an "Infant Death Registry Report Form" and implemented it across the country to obtain systematic and reliable information on maternal and child health and to develop new goals to achieve higher quality health services. The scope of the form was broadened in 2006 and renamed "Perinatal and Infant Death Registry Report Form". The follow-up of pregnant women, family status, place of birth, and some information about the cause of death have been collected using this form. In 2009, the Infant Mortality Inspection Committee was constituted, with the Director of Health or the Assistant Director of Health as president in each province of the country. At the end of each month, reports by the Infant Mortality Inspection Committees have been sent to the General Directorate of DCAH.

We could not access reliable data for the first two years of this project since data were entered into electronic media only after 2007.

The most common ten major causes of infant deaths defined as prematurity, congenital anomalies, sepsis, congenital heart diseases (CHD), respiratory distress syndrome (RDS), perinatal asphyxia, lower respiratory system infections (LRSI), sudden infant death syndrome (SIDS), metabolic diseases, and birth injury were evaluated. To find out changes in the causes of death accompanying improved NMR and IMR, causes of deaths were analyzed by year. The data on possible risk factors which affect IMR and NMR such as the numbers of infants per paediatrician, number of pregnant women per obstetrician, infants per physician, infants per midwife, infant follow-up, neonatal intensive care unit (NICU) beds per 1,000 live birth, staff trained within the Neonatal Resuscitation Programme (NRP) and the rates of hospital birth in which trained attendants assisted, mode of delivery, antenatal care ( $>$ four visits), and Measles-Mumps-Rubella (MMR) vaccination were recorded from the same national database.

All data were evaluated by 12 geographical regions to show regional differences. The study was carried out with the written permission of the Board of Health Policies, the Ministry of Health of Turkey.

\section{Statistical Analyses}

Available data on IM and NM from 2007-2012 were entered into the SPSS software (SPSS 16.0). Descriptive analyses were carried out to define changes in IMR and NMR by year and geographical regions. Differences among mortality rates according to year and regions were analyzed by Chi square test and tests for trends. Correlation and regression analyses were performed to define the association between IM and NM and possible risk factors such as the number of infant per paediatrician, number of pregnant women per obstetrician, hospital birth, caesarean delivery, antenatal care, NICU beds, NRP training, MMR vaccination and infant follow up. The level of significance was set at 0.05 in all comparisons.

\section{RESULTS}

\section{Changes in IMR and NMR}

The number of live births, stillbirths, premature births, neonatal and infant deaths in whole Turkey are shown in Table 1. A total of 94,038 infant deaths were evaluated between 2007 and 2012. Overall, Turkey IMR and NMR exhibited a marked decline from 2007 (16.4 and 12.2) through 2012 (9.7 and 6.3) $(\mathrm{p}=0.008, \mathrm{p}=$ 0.009, respectively) (Fig. 1). As shown, after significant declines from 2007, mortality rates plateaued from 2010 through 2012.

The changes in IMR showed regional differences. IMR was lower in Istanbul, West Marmara, Aegean, East Marmara, West and East Black Sea regions compared to Turkey average $(\mathrm{p}<$ 0.001). Similarly, NMR was lower in Istanbul, West Marmara, Aegean, East Marmara, West and East Black Sea, North Black Sea, and North East Anatolia regions $(\mathrm{p}<0.001)$. In Istanbul, a well served region, IMR and NMR were 10.7 and 8.2 in 2007 and declined to 7.5 and 5.0 in 2012 (30.0\% and 39.1\% reduction, respectively). In South East Anatolia, a socioeconomically disadvantaged region, the reduction in IMR and NMR were more prominent; IMR and NMR declined from 20.2 and 16.5 in 2007 to 12.9 and 8.3 in 2012 (36.1\% and $49.7 \%$ reduction, respectively). Fig. 2 and 3 shows IMR and NMR by geographical regions between 2007 and 2012. IMR and NMR were the highest in the

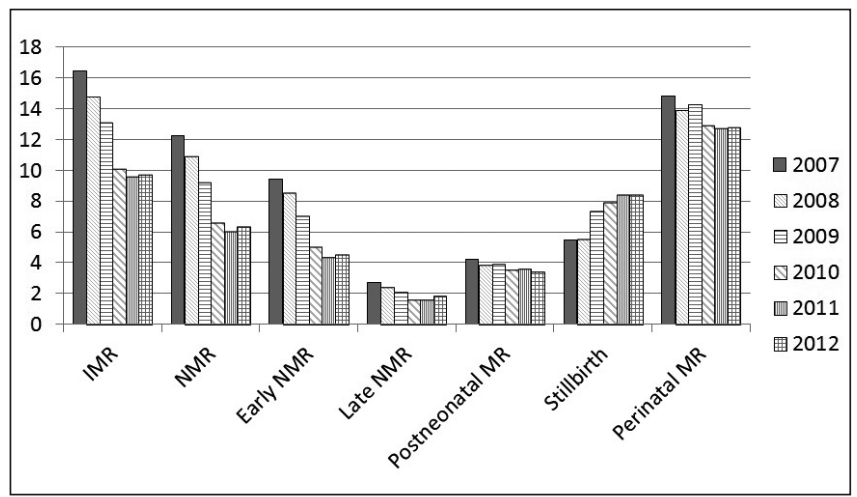

Fig. 1. Mortality rates (per 1,000 live births) by years. IMR: Infant Mortality Rate, NMR: Neonatal Mortality Rate.

Table 1. The numbers of live births, stillbirths, premature birth, neonatal and infant deaths in Turkey: 2007-2012

\begin{tabular}{|l|c|c|c|c|c|}
\hline Years & Live birth & Stillbirth & Premature birth & Neonatal death & Infant death \\
\hline 2007 & $1,289,992$ & 7,095 & 141,899 & 15,737 & 21,155 \\
\hline 2008 & $1,295,511$ & 7,125 & 147,688 & 14,121 & 19,173 \\
\hline 2009 & 1,265071 & 9,235 & 150,543 & 11,638 & 16,572 \\
\hline 2010 & $1,258,252$ & 9,940 & 150,990 & 8,304 & 12,708 \\
\hline 2011 & $1,244,673$ & 10,455 & 149,360 & 7,468 & 11,948 \\
\hline 2012 & $1,286,828$ & 10,809 & 154,419 & 8,107 & 12,482 \\
\hline
\end{tabular}




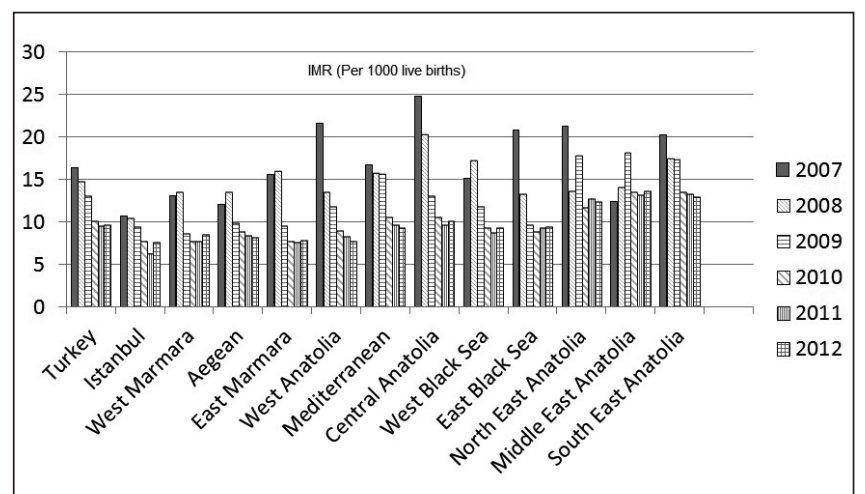

Fig. 2. Infant mortality rates (IMR) (per 1,000 live births) by geographical regions, Turkey; 2007-2012.

Middle East Anatolia region (13.6 and 8.8), while they were the lowest (7.5 and 5.0) in Istanbul by 2012 .

\section{Changes in Causes of Infant and Neonatal Death}

The most common ten major causes of infant deaths by year are given in Table 2. While the rates of RDS $(p=0.01)$, SIDS $(p=0.02)$, and metabolic diseases $(p=0.0001)$ increased, rates of congenital anomalies $(\mathrm{p}=0.01)$ and birth injuries $(\mathrm{p}=0.02)$ decreased. In 2012, when the causes of deaths were analyzed separately by regions, prematurity was higher in Aegean region (34.7\%), East Marmara (30.0\%) and West Anatolia (34.5\%) compared to Turkey average $(26.9 \%)(p=0.001)$; RDS was higher in West Black Sea region $(14.8 \%)$ and South East Anatolia (10.5\%) compared to country average $(7.3 \%)(p=0.001)$. Deaths due to congenital anomalies were common in West (14.5\%) and East Marmara (12.5\%) compared with country average of $10.3 \%$. CHD was most commonly a cause of death in Istanbul (17.4\%) and West Anatolia (19.0\%) compared to Turkey average of $11.7 \%$ ) ( $p<0.05$, for both comparisons), while sepsis was more common in South East Anatolia $(10.1 \%)$ compared to Turkey average of $8.5 \%(p=0.03)$.

\section{The Main Risk Factors Related to Infant and Neo- natal Mortality}

The association between IM and possible risk factors were investigated. IMR was significantly increased with the number of infants per paediatrician $(p=0.001)$, per doctor $(p=0.001)$, and

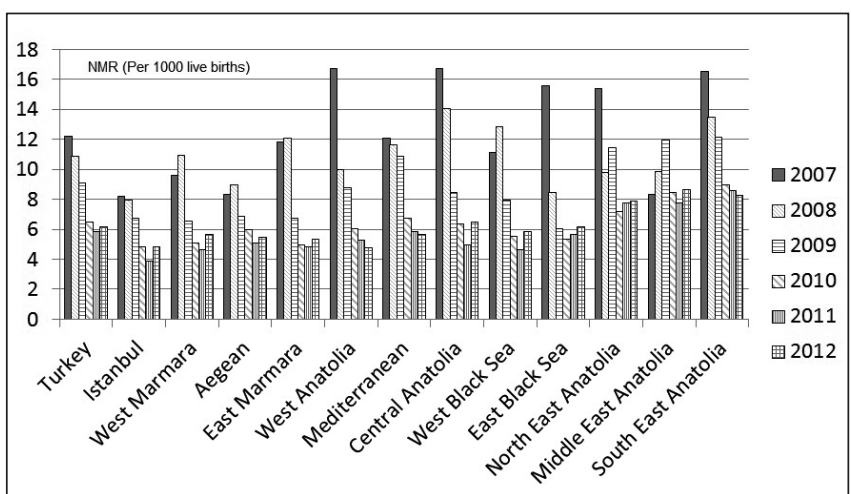

Fig. 3. Neonatal mortality rates (NMR) (per 1,000 live births) by geographical regions, Turkey; 2007-2012.

per midwife $(p=0.02)$. However, increased numbers of hospital birth $(p=0.002)$, caesarean delivery $(p=0.001)$, adequate antenatal care ( $>$ four visits) $(p=0.001)$, infant follow-up $(p=0.002)$, and staff trained within NRP $(p=0.001)$ significantly reduced IMR. The rate of MMR vaccination at 12 month of age and the number of NICU beds per 1,000 live births had no effect on IM ( $\mathrm{p}>0.05)$ (Fig. 4).

Neonatal deaths significantly increased with increasing numbers of infants per paediatrician $(\mathrm{p}=0.001)$, infants per doctor $(p=0.001)$, and infants per midwife $(p=0.01)$, while were

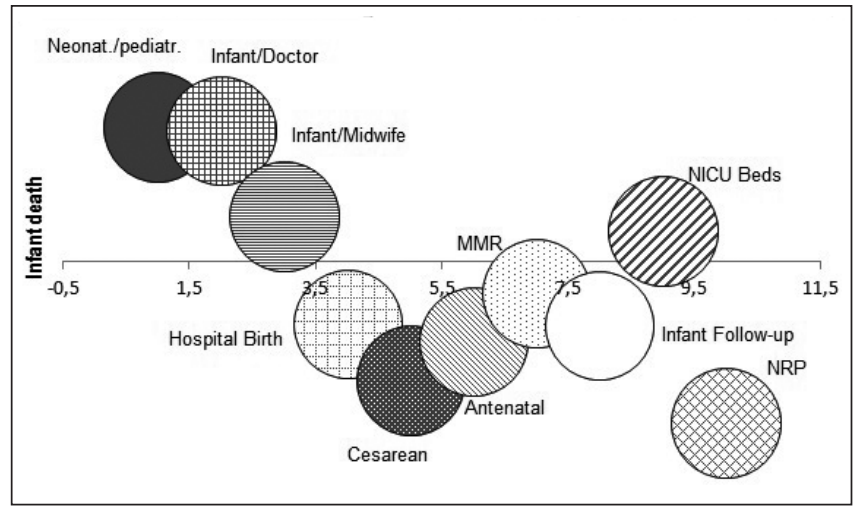

Fig. 4. The association between infant death and possible risk factors. MMR: Measles-Mumps-Rubella vaccination, NICU: Neonatal Intensive Care Unit, NRP: Neonatal Resuscitation Programme.

Table 2. The most common ten major causes of infant deaths in Turkey: 2007-2012

\begin{tabular}{|l|c|c|c|c|c|c|c|c|c|c|}
\hline Years & $\begin{array}{c}\text { Prematurity } \\
(\%)\end{array}$ & $\begin{array}{c}\text { Congenital } \\
\text { anomalies } \\
(\%)\end{array}$ & Sepsis $(\%)$ & $\begin{array}{c}\text { Congeni- } \\
\text { tal heart } \\
\text { diseases } \\
(\%)\end{array}$ & $\begin{array}{c}\text { Respirato- } \\
\text { ry distress } \\
\text { syndrome } \\
(\%)\end{array}$ & $\begin{array}{c}\text { Perinatal } \\
\text { asphyxia } \\
(\%)\end{array}$ & $\begin{array}{c}\text { Lower } \\
\text { respiratory } \\
\text { system } \\
\text { infections } \\
(\%)\end{array}$ & $\begin{array}{c}\text { Sudden in- } \\
\text { fant death } \\
\text { syndrome } \\
(\%)\end{array}$ & $\begin{array}{c}\text { Metabolic } \\
\text { diseases } \\
(\%)\end{array}$ & $\begin{array}{c}\text { Birth injury } \\
(\%)\end{array}$ \\
\hline 2007 & 31.13 & 17.2 & 8.0 & 9.1 & 3.6 & 5.8 & 4.0 & 1.9 & 1.1 & 1.6 \\
\hline 2008 & 29.3 & 15.9 & 11.5 & 6.7 & 3.5 & 6.6 & 2.3 & 1.7 & 1.0 & 0.7 \\
\hline 2009 & 27.7 & 14.0 & 9.8 & 4.8 & 3.3 & 4.0 & 2.0 & 1.5 & 1.3 & 0.5 \\
\hline 2010 & 23.6 & 9.7 & 9.3 & 6.6 & 6.0 & 2.6 & 2.1 & 3.0 & 2.1 & 0.3 \\
\hline 2011 & 23.0 & 10.2 & 10.0 & 9.7 & 6.7 & 3.2 & 3.8 & 3.6 & 2.8 & 0.1 \\
\hline 2012 & 26.9 & 10.3 & 8.5 & 11.7 & 7.3 & 3.5 & 1.5 & 4.0 & 3.4 & 0.2 \\
\hline
\end{tabular}




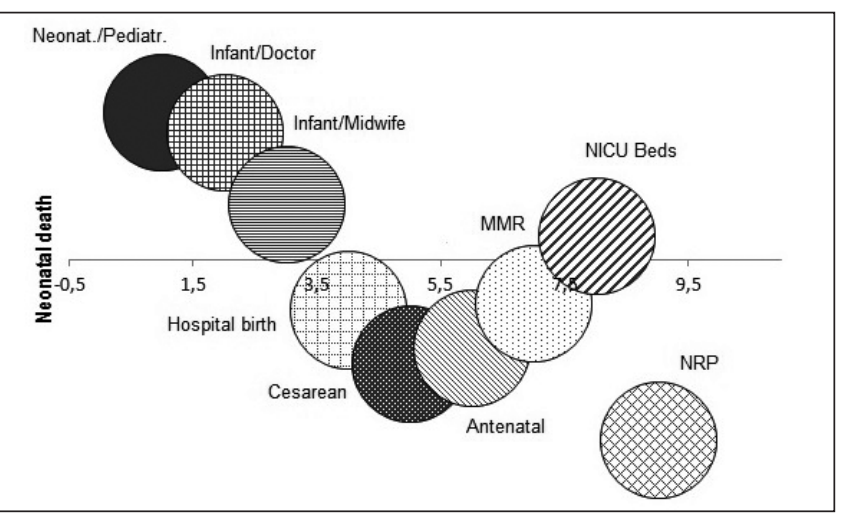

Fig. 5. The association between neonatal death and possible risk factors. MMR: Measles-Mumps-Rubella vaccination, NICU: Neonatal Intensive Care Unit, NRP: Neonatal Resuscitation Programme.

decreasing with increased numbers of hospital birth $(p=0.02)$, caesarean delivery $(p=0.001)$, antenatal care $(p=0.001)$, infant follow-up $(p=0.04)$, and staff trained within NRP $(p=0.001)$. The number of NICU beds per 1,000 live births had no effect on NMR ( $p=0.26$ ) (Fig. 5). The possible risk factors affecting IMR and NMR were investigated by year and region. The number of infants per paediatrician was 772 in 2007 and 618 in 2012, exhibiting a significant reduction $(\mathrm{p}=0.001)$. The number of pregnant women per obstetrician was also significantly reduced from 631 in 2007 to 623 in $2012(p=0.001)$. The number of infants per paediatrician was significantly higher in Istanbul, Mediterranean, Central Anatolia, North East, Middle East, and South East Anatolia regions compared with the Turkey average $(p<0.001)$. The number of pregnant women per obstetrician was also high in the same regions of the country. Antenatal care coverage rate increased from $69.2 \%$ (average follow-up number of 4.4) in 2007 to $92.3 \%$ (average follow-up number of 4.5 ) in $2012(\mathrm{p}=0.01$ ). Antenatal care rate was significantly lower in Istanbul, North East, Middle East, and South East Anatolia regions compared to national average $(\mathrm{p}<0.001)$.

From 2007 to 2012, there have been significant rises in the percentages of hospital births $(84.8 \%$ in 2007 and 96.8 in 2012, $\mathrm{p}=0.001)$ and caesarean deliveries $(36.3 \%$ in 2007 and $47.9 \%$ in 2012, $\mathrm{p}=0.001)$. However, primary caesarean rates did not change significantly (26.0\% in 2007 and 24.6 in 2012, p = 0.07). The percentage of hospital births were higher in Istanbul, West Marmara, Aegean, West Anatolia, Mediterranean and West Black Sea regions compared to Turkey average. Caesarean delivery rates were lower in Central Anatolia, North East Anatolia, Middle East and South East regions $(\mathrm{p}<0.001)$.

The numbers of the staff received NRP per 1,000 live birth increased from 14.1 in 2007 to 24.0 in $2012(p=0.001)$ all over the country. The numbers of NICU beds ( 2.2 in 2008 compared to 5.8 in 2012, p = 0.003) and mechanical ventilator ( 1.26 in 2007 compared to 2.5 in 2012, $\mathrm{p}=0.001$ ) per 1,000 live births significantly increased by years, especially in Aegean, Mediterranean, West Black Sea, and South East regions.

The rates of infant follow-up significantly increased from 2007 $2012(86.4 \%$ in $2007,96.3 \%$ in $2012, p=0.03)$, while Istanbul, West Anatolia, North East, Middle East, and South East Anatolia region rates exceeded national average. The percentage of MMR vaccination did not change significantly during the study period
( $95.2 \%$ in 2007 and $93.7 \%$ in $2012, p=0.40$ ). However, regional differences were noted, vaccination rates were lower in North East, Middle East and South East Anatolia regions ( $p>0.001)$.

\section{DISCUSSION}

The IMR of Turkey decreased from 16.4 in 2007 to 10.1 in 2010, and 9.7 in 2012, exhibiting a remarkably decreasing trend. Similarly, NMR has showed a decreasing pattern (12.2 in 2007, 6.6 in 2010, and 6.3 in 2012).

There are striking cross-country and within-country variations in IMR. The highest IMRs have been reported in Angola (174.9), Afghanistan (149.2), and Nigeria (112.2) while IMRs in the Western European (WE) nations of the United Kingdom (UK), France, Germany, and Nordic countries ranged from 2.5 to $4.7(1,9)$. The data of the World Health Statistics of 2011 showed that NM constituted $60 \%$ of U5MR in Turkey, 54\% in European region, 50\% in upper middle income group, and $40 \%$ in the world $(10,11)$. In most high-income countries, NMR ranges between 1.0 and 4.0, and neonatal deaths in these countries make up only $1.4 \%$ of the total neonatal deaths worldwide (12). Although Turkey's recent IMR and NMR are higher than those of other developed countries, they are much lower than those of the most Organization for Economic Co-operation and Development (OECD) nations $(1,9)$.

Wide within-country variations in birth outcomes have been reported even in WE nations $(13,14)$. In Turkey, previous reports revealed that IMR and NMR in rural areas were approximately 1.5 times higher than those in urban areas; the East region had the highest mortality rates (7). Recent data suggest that health care that is equally available to all citizens reduces social disparities in mortality (15). The new human resource policies collectively helped to address staff shortages in the Turkish health system and to reduce inequities; the number of health human resources doubled between 2002 and 2012. In the East region, U5MR declined from 62.8 in 1993 to 27.7 in $2008(5,7)$. We found that the difference between well served and less well served regions is narrowed; South East region showed $36.1 \%$ and $49.7 \%$ decrement in IMR and NMR, while Istanbul showed $30.0 \%$ and $39.1 \%$ decrement from 2007 to 2012.

Perinatal mortality rate have influenced lowered NMR. In Turkey, perinatal mortality rate was 24.0 in 2003 (16). Afterwards, this rate strikingly decreased to 14.8 in 2007 and then plateaued from 2010 (12.9) through 2012 (12.8). The reasons may include a number of operating perinatal healthcare centres and localization of advanced neonatal care networks established in Turkey. Stillbirth is a devastating pregnancy outcome that is estimated to occur in 2.65 million cases globally each year (17-19). In a recent Uganda research, it was reported that antepartum hemorrhage, ruptured uterus, severe preeclampsia, eclampsia, and the syndrome of hemolysis, elevated liver enzymes, low platelets (HELLP syndrome) had increased the risk of still birth or neonatal deaths (20). In the current study, the increase in stillbirth rate may be explained by better medical data records.

In developed countries, leading causes of infant deaths are prematurity and congenital anomalies, while they are listed as prematurity, infections, birth injuries, and asphyxia in developing countries (21). A recent research showed that neonates whose preceding sibling had died as a neonate in the mothers' lifetime 
pregnancy history were more likely to die than those with a living sibling (22). Based on data of the Turkish Statistical Institute (1991), the leading causes of infant deaths were birth injury, perinatal asphyxia, and other causes of perinatal mortality, followed by LRSI, and heart diseases. In 1996, major causes of infant deaths were reported as perinatal causes, meningococcal infections, and heart diseases (23). While the rates of RDS, SIDS and metabolic diseases increased from 2007-2012, rates of congenital anomalies and birth injuries were decreasing. It is shown that causes of deaths have changed with improvement in IMR and NMR, resembling to those of developed countries.

In almost all high- and middle-income countries of the world, preterm birth is the leading cause of child death (24). Data on preterm birth rates are not routinely collected in many countries and, where available, are frequently not reported using a standard international definition. Recent estimates of preterm birth rates (all live births before 37 completed weeks) for 184 countries in 2010 and a time series for 65 countries with sufficient data suggest that the rate of preterm birth may reach 14.9 million (25). A recent study from Sweden showed that proactive perinatal care decreased mortality without increasing the risk of neurodevelopmental impairment at 2.5 years of corrected age in extremely preterm infants (26). Premature birth rate is about $11-12 \%$ in Turkey $(7,16)$. Preterm deaths were more frequent in Aegean, East Marmara and West Anatolia regions, the well-served parts of the country. Preterm infants have a risk of neonatal death 13 times greater than that of full-term infants $(27,28)$. We observed that prematurity and its complications were the most important causes of IM in all study years.

Congenital anomalies (other than heart anomalies) are the second or third among the most common aetiologies of IM. Close antenatal follow-up for genetic anomalies and preconception supplementation with folic acid are the strategies used to prevent births with congenital anomalies (29). Intake of folic in the periconceptional period reduces the risk of neural tube defects (NTD). Turkey is one of the low-income countries with high prevalence rate of NTDs at birth. A national survey conducted in 1993-1994 showed a perinatal prevalence of 4.3 and 4.9 NTDs per 1,000 births in Northern and Eastern Anatolia, respectively, compared with 3.0 per 1,000 for the whole country (30). Currently, in Turkey, women who are planning marriage or pregnancy are advised to take $400 \mu \mathrm{g}$ of supplemental folic acid every day starting before conception, through the end of the first trimester of pregnancy. We observed that within infant deaths the ratio of congenital anomalies decreased from $17.2 \%$ in 2007 to $10.3 \%$ in 2012. Education of the population and prevention of consanguineous marriages would also decrease the incidence of congenital anomalies in the future.

One-year survival for infants with critical CHDs has been improving over time, but mortality is still high (31). It was reported that prenatal diagnosis was associated with lower than one year survival rate for infants with isolated critical CHDs (32). CHD screening by pulse oximeter before discharge may prevent delay in diagnosis of critical CHD (33). Critical CHDs are still important causes of IM and NM in Turkey. The lack of appropriate health centres that can perform cardiovascular surgery for such babies is the leading reason for NM due to critical CHD. The Ministry of Health has taken important steps in increasing the number of cardiovascular surgery centres and improving patient transport.
Today, a total of 23 centres (public, private, and university hospitals) deal with paediatric cardiovascular surgery in Turkey. Neonatal cardiovascular surgery can be performed only in one third of them (34). Nowadays, the Ministry of Health has planned to start a nationwide CHD screening programme in Turkey.

One indicator for monitoring progress of the Millennium Development Goals (MDG) Target 5A (the maternal mortality ratio) was the proportion of births attended by skilled health personnel (35). In a study from Ethiopia evaluating the national data of African countries, it was found that skilled delivery attendance was associated with significant reduction of maternal, foetal and neonatal mortality (36). Currently in Turkey, within HTP, risk caring pregnant women living in rural areas, where might be problems during transportation to the health centre, have been hospitalized from the last trimester to delivery $(5,37)$. This way, the proportion of newborns born in health facilities increased from $49.7 \%$ in the Turkey Demographic and Health Survey (TDHS) 1993 to $89.7 \%$ in the TDHS 2008 (7). In this report, it was detected that hospital birth and caesarean delivery rates increased by years, without a prominent change in primary caesarean rates. High caesarean rates may be related to obstetrician's choice at high risk pregnancies in hospital births.

\section{CONCLUSION}

In this report, we reviewed improvements in IMR and NMR for the last six years in Turkey, finding remarkably encouraging advances. The slow decline in IMR and NMR after 2010 reflects the need of new strategies. Any interventions should target the common causes of death and defined risk factors, especially in socioeconomically disadvantaged eastern regions.

\section{Conflict of Interests}

None declared

\section{REFERENCES}

1. UNICEF; World Health Organization; The World Bank; United Nations. Levels \& trends in child mortality: estimates developed by the UN Interagency Group for Child Mortality Estimation. Report 2012 [Internet]. New York: Unicef; 2012 [cited 2015 May 3]. Available from: http://www. who.int/maternal_child_adolescent/documents/levels_trends_child_mortality_2012.pdf?ua=1.

2. The Ministry of Health of the Republic of Turkey. Health statistics yearbook, 2011 [Internet]. Ankara: The Ministry of Health of the Republic of Turkey; 2012 [cited 2015 May 3]. Available from: http://sbu.saglik. gov.tr/Ekutuphane/kitaplar/health_statistics_yearbook_2011.pdf.

3. World Health Organization. Global Health Observatory data repository. Infant mortality. Data by country [Internet]. Geneva: WHO; 2015 [cited 2015 May 3]. Available from: http://apps.who.int/gho/data/node. main.526.

4. Akdag R. Health Transformation Program 2003-11. Progress report. Ankara: Republic of Turkey, Ministry of Health; 2013.

5. Atun R, Aydın S, Chakraborty S, Sümer S, Aran M, Gürol I, et al. Universal health coverage in Turkey: enhancement of equity. Lancet. 2013 Jul 6;382(9886):65-99.

6. Turkish Statistical Institute. Statistics on child, 2014. Ankara: Turkish Statistical Institute; 2015.

7. Turkey Demographic and Health Survey, 2008. Ankara: Hacettepe University Institute of Population Studies; 2009.

8. World Health Organization. International statistical classification of infectious diseases and related health problems. Geneva: WHO; 2004. 
9. Organization for Economic Co-operation and Development. OECD Family Database [Internet]. Paris: OECD; 2011 [cited 2015 May 3]. Available from: http://www.oecd.org/els/family/database.htm.

10. World Health Organization. World health statistics 2011. Geneva: WHO; 2011.

11. United Nations Children's Fund. Committing to child survival: a promise renewed. New York: UNICEF; 2012.

12. Oestergaard MZ, Inoue M, Yoshida S, Mahanani WR, Gore FM, Cousens $\mathrm{S}$, et al.; United Nations Inter-Agency Group for Child Mortality Estimation and the Child Health Epidemiology Reference Group. Neonatal mortality levels for 193 countries in 2009 with trends since 1990: a systematic analysis of progress, projections, and priorities. PLoS Med. 2011 Aug;8(8):e1001080. doi: 10.1371/journal.pmed.1001080.

13. Macdorman MF, Mathews TJ. Recent trends in infant mortality in the United States. NCHS Data Brief. 2008 Oct;(9):1-8.

14. Kim D, Saada A. The social determinants of infant mortality and birth outcomes in Western developed nations: a cross-country systematic review. Int J Environ Res Public Health. 2013 Jun 5;10(6):2296-335.

15. Carlsen F, Grytten J, Eskild A. Maternal education and risk of offspring death; changing patterns from 16 weeks of gestation until one year after birth. Eur J Public Health. 2014 Feb;24(1):157-62.

16. Turkey Demographic and Health Survey, 2003. Ankara: Hacettepe University Institute of Population Studies; 2004.

17. Gordon A, Raynes-Greenow C, McGeechan K, Morris J, Jeffery H. Risk factors for antepartum stillbirth and the influence of maternal age in New South Wales Australia: a population based study. BMC Pregnancy Childbirth. 2013 Jan 16;13:12. doi: 10.1186/1471-2393-13-12.

18. MacDorman MF, Hoyert DL, Martin JA, Munson ML, Hamilton BE. Fetal and perinatal mortality, United States, 2003. Natl Vital Stat Rep. 2007 Feb 21;55(6):1-17.

19. World Health Organization. Neonatal and perinatal mortality: country, regional, and global estimates. Geneva: WHO; 2006.

20. Nakimuli A, Mbalinda SN, Nabirye RC, Kakaire O, Nakubulwa S, Osinde $\mathrm{MO}$, et al. Still births, neonatal deaths and neonatal near miss cases attributable to severe obstetric complications: a prospective cohort study in two referral hospitals in Uganda. BMC Pediatr. 2015 Apr 17;15:44. doi: 10.1186/s12887-015-0362-3.

21. Wennemo I. Infant-mortality, public policy, and inequality - a comparison of 18 industrialized countries 1950-85. Sociol Health Illn. 1993;15(4):429-46.

22. Nonyane BA, Williams EK, Blauvelt C, Shah MR, Darmstadt GL, Moulton L, et al. Clustering of neonatal deaths in Bangladesh: results from the Projahnmo studies. Paediatr Perinat Epidemiol. 2013 Mar;27(2):16571.

23. Vital Statistics, 1992-1999. Ankara: Turkish Statistical Institute.

24. Liu L, Johnson HL, Cousens S, Perin J, Scott S, Lawn JE, et al.; Child Health Epidemiology Reference Group of WHO and UNICEF. Global, regional, and national causes of child mortality: an updated systematic analysis for 2010 with time trends since 2000. Lancet. 2012 Jun 9;379(9832):2151-61.
25. Blencowe H, Cousens S, Chou D, Oestergaard M, Say L, Moller AB, et al.; Born Too Soon Preterm Birth Action Group. Born too soon: the global epidemiology of 15 million preterm births. Reprod Health. 2013;10 Suppl 1:S2. doi: 10.1186/1742-4755-10-S1-S2.

26. Serenius F, Blennow M, Maršál K, Sjörs G, Källen K; EXPRESS Study Group. Intensity of perinatal care for extremely preterm infants: outcomes at 2.5 years. Pediatrics. 2015 May;135(5):e1163-72. doi: 10.1542/ peds.2014-2988

27. Yasmin S, Osrin D, Paul E, Costello A. Neonatal mortality of low-birthweight infants in Bangladesh. Bull World Health Organ. 2001;79(7):60814.

28. Beck S, Wojdyla D, Say L, Betran AP, Merialdi M, Requejo JH, et al. The worldwide incidence of preterm birth: a systematic review of maternal mortality and morbidity. Bull World Health Organ. 2010 Jan;88(1):31-8.

29. Czeizel AE, Dudás I, Vereczkey A, Bánhidy F. Folate deficiency and folic acid supplementation: the prevention of neural-tube defects and congenital heart defects. Nutrients. 2013 Nov 21;5(11):4760-75. doi: 10.3390/nu5114760.

30. Tekkesin N, Taser F. Folic acid usage and awareness in pregnant women in Istanbul, Turkey. J Hosp Admin. 2012;1(1):9-14.

31. Oster ME, Lee KA, Honein MA, Riehle-Colarusso T, Shin M, Correa A Temporal trends in survival among infants with critical congenital heart defects. Pediatrics. 2013 May;131(5):e1502-8. doi: 10.1542/peds.20123435 .

32. Oster ME, Kim CH, Kusano AS, Cragan JD, Dressler P, Hales AR, et al. A population-based study of the association of prenatal diagnosis with survival rate for infants with congenital heart defects. Am J Cardiol. 2014 Mar 15;113(6):1036-40.

33. Granelli Ad, Ostman-Smith I. Noninvasive peripheral perfusion index as a possible tool for screening for critical left heart obstruction. Acta Paediatr. 2007 Oct;96(10):1455-9.

34. Republic Of Turkey, Ministry Of Health. Prevention and control program for cardiovascular diseases: strategic plan and action plan for the risk factors [Internet]. Ankara: 2009 [cited 2015 May 3]. Available from: http://Sbu.Saglik.Gov.Tr/Ekutuphane/Kitaplar/T4.Pdf.

35. World Health Organization. Millennium development goals in the WHO European region: a situational analysis at the eve of the five-year countdown. Copenhagen: WHO Regional Office for Europe; 2010.

36. Berhan Y, Berhan A. Skilled health personnel attended delivery as a proxy indicator for maternal and perinatal mortality: a systematic review. Ethiop J Health Sci. 2014 Sep;24 Suppl:69-80.

37. Yalçin SS, Tezel B, Köse MR, Tugay D, Mollahaliloğlu S, Erkoç Y Changes and determinants in under-five mortality rate in Turkey since 1988. Cent Eur J Public Health. 2013 Jun;21(2):80-7.

Received September 10, 2014 Accepted in revised form May 3, 2015 